\title{
Remuneração estratégica: percepção dos colaboradores de instituiç̧eses financeiras públicas e privadas em Cascavel
}

\author{
Roberto Francisco de Souza Mestre em Contabilidade. Universidade Estadual do Oeste do Paraná (UNIOESTE) - Brasil. \\ robertofsouzaj@gmail.com \\ Leila Aparecida Scherer Weiss Mestre em Contabilidade. Universidade Estadual do Oeste do Paraná (UNIOESTE) - Brasil. \\ leila.weiss83@gmail.com \\ Adhmir Renan Voltolini Gomes Mestre em Contabilidade. Universidade Estadual do Oeste do Paraná (UNIOESTE) - \\ Brasil.adhmir.renan@gmail.com \\ Samuel Lyncon Leandro de Lima Mestre em Contabilidade. Universidade Estadual do Oeste do Paraná (UNIOESTE) - Brasil. \\ samuellynconleandro@gmail.com \\ Delci Grapegia Dal Vesco Doutora em Contabilidade e Administração. Universidade Regional de Blumenau (FURB) - \\ Brasil. delcigrape@gmail.com
}

\section{RESUMO}

Esta pesquisa tem como objetivo analisar a percepção dos colaboradores de instituições financeiras públicas e privadas sobre a remuneração estratégica. A metodologia utilizada no estudo classifica-se, quanto aos objetivos, descritiva, quanto aos procedimentos, levantamento ou surveye quanto à abordagem do problema, quantitativa. Os dados foram coletados através da aplicação de um questionário no período de Maio a J ulho de 2017 com colaboradores das agências bancárias e cooperativas de crédito da cidade de Cascavel, totalizando 154 respondentes. A análise dos dados deu-se por meio de análise multivariada como Análise Fatorial e Alfa de Cronbach. Os resultados demonstraram que a percepção dos colaboradores de instituições públicas é explicada em $69,08 \%$ e o componente que mais explica essa percepção consiste no Status. No que se refere à percepção dos colaboradores de instituições privadas, foi explicada em $62,63 \%$ e o principal componente refere-se aos Incentivos Psicológicos e Sociais. Conclui-se que a remuneração direta, apesar de ser um componente que explica a remuneração de colaboradores de ambas instituições, não foi elencado como o mais explicativo.

Palavras-chave: Colaboradores. Motivação. Percepção. Remuneração Estratégica. Sistemas de Incentivo.

\section{Strategic remuneration: perception of employees of public and private financial institutions in Cascavel}

\begin{abstract}
This research aims to analyze the perception of employees of public and private financial institutions on strategic remuneration. The methodology used in the study is classified, as far as the objectives, descriptive, regarding the procedures, survey or survey and as to the approach of the problem, quantitative. The data were collected through the application of a questionnaire in the period from May to July 2017 with employees of bank branches and credit cooperatives in the city of Cascavel, totaling 154 respondents. Data analysis was performed through multivariate analysis such as Factorial Analysis and Cronbach's Alpha. The results showed that the perception of employees of public institutions is explained in $69.08 \%$, and the component that most explains this perception consists of Status. Regarding the employees' perception of private institutions, it was explained in $62.63 \%$, and the main component refers to the Psychological and Social Incentives. It is concluded that direct remuneration, despite being a component that explains the remuneration of employees of both institutions, was not listed as the most explanatory.
\end{abstract}

Keywords: Collaborators. Motivation. Perception. Strategic Remuneration. Incentive Systems 


\section{INTRODUÇÃO}

A remuneração dos gestores vem sofrendo mudanças ao longo do tempo, assim as organizações procuram adequar os interesses individuais ao melhor desempenho da entidade, vinculando assim, ao desempenho à recompensa. Dessa forma, os sistemas de incentivo, são utilizados pelas organizações como ferramentas motivacionais, para conduzir os gestores há um comportamento que priorize os interesses das organizações, alinhando-os a seus próprios desejos (Merchant, Van Der Stede, \& Zheng, 2003).

Em muitos casos, as metas pessoais dos colaboradores podem não estar em consonância com os objetivos da instituição, assim podem causar uma série de problemas para as organizações. Esses problemas podem se agravar quando existe uma política de remuneração que promove metas inalcançáveis (Oyadomari, Cesar, Souza, \& Oliveira, 2009). Neste sentido, os sistemas de incentivos gerenciais são utilizados como ferramentas de controle gerencial, pois procuram cumprir o papel motivacional de induzir o comportamento dos gestores em direção aos objetivos organizacionais e garantir um nível de desempenho. (Anthony \& Govindarajan, 2012).

Diante disso, são identificados três elementos centrais dos sistemas de remuneração estratégica. 0 primeiro refere-se à remuneração fixa, esta é segregada pela remuneração funcional, pelo salário indireto e pela previdência complementar, por competência e por habilidade. Já o segundo, está associado à remuneração por desempenho, sendo este elemento composto pela remuneração variável e participação acionária. 0 terceiro elemento são as formas especiais, estas são criadas para atingir os resultados excepcionais, e abrangem diversas modalidades, desde bônus, ações, benefícios e empréstimos a taxas inferiores ao mercado (Wood Júnior \& Picarelli Filho, 2004).

Para assegurar o comportamento e motivação dos colaboradores de acordo com o objetivo da organização, as empresas procuram proporcionar maior atratividade para os colaboradores. Assim, as organizações oferecem além do salário fixo tradicional, qualidade de vida, pacote de benefícios, oportunidades de crescimento e remuneração justa, com o intuito de beneficiar os colaboradores com outras formas de pagamentos (Gheno \& Berlitz, 2011).

Surge então dentro das organizações a remuneração estratégica como uma nova forma de gestão empresarial, que tem como principal objetivo a eficiência e a eficácia em função de resultados positivos (Brandão, Rosa \& Junior, 2012). Enquanto o sistema tradicional remunera as pessoas somente com as exigências do cargo, a remuneração estratégica procura beneficiar as pessoas, que contribuem, de alguma forma, para o aumento dos ganhos e nos resultados da organização, auxiliando no diferencial competitivo da mesma (Gheno \& Berlitz, 2011).

Em estudos anteriores Reis Neto (2004) investiga a influência da remuneração variável na motivação e desempenho por meio da percepção dos colaboradores. E os achados demonstraram a inexistência significativa, pois não afetou a avaliação dos entrevistados. No setor público, Albergaria (2010) teve como objeto de estudo a percepção dos servidores sobre o prêmio por produtividade e relações com desempenho funcional e adaptação social. A influência encontrada referente aos aspectos pessoais e funcionais destacaramse por meio do nível de escolaridade, seguidos de remuneração mensal.

Investigando os papéis de lideranças empresariais por meio de um plano de remuneração variável e os processos de repercussões pessoais e profissionais, Fisher (2013) evidencia a necessidade de os líderes estarem engajados nos processos de implementação e conhecer os planos de remuneração variável. Nessa perspectiva, os colaboradores das instituições financeiras detêm um amplo conjunto de remunerações estratégicas, proporcionando uma conjunção passível de comparação entre setor público e privado, dado que a percepção desses profissionais pode contribuir com uma concepção privilegiada, e ainda é uma parte inexplorada até o momento.

Com base no exposto, o estudo tem a seguinte pergunta: Qual a percepção dos colaboradores de instituições financeiras públicas e privadas sobre a remuneração estratégica? Dessa forma, o objetivo deste estudo é analisar a percepção dos colaboradores de instituições financeiras públicas e privadas sobre a remuneração estratégica. Considerando a importância do papel das pessoas para o desenvolvimento das organizações, esta pesquisa pretende contribuir para o entendimento, aprimoramento, aplicação e verificação da efetividade da remuneração estratégica, com intuito de beneficiar as organizações que adotam essa 
sistemática e, auxiliar na identificação da percepção sobre a motivação de seus colaboradores com o uso da remuneração estratégica como mecanismo de incentivo.

Diante disso, a pesquisa foi organizada em cinco seções. Essa primeira seção apresentou a introdução, e a seguir, na segunda seção, foi apresentada a fundamentação teórica da pesquisa. J á na terceira seção, foram detalhados os aspectos metodológicos desse estudo. Na quarta seção, foram analisados os dados e discutidos os principais achados da pesquisa. Por fim, na quinta seção, foram manifestas as considerações finais, a partir do conteúdo trabalhado nessa pesquisa.

\section{REFERENCIAL TEÓRICO}

Este tópico aborda as teorias referentes à remuneração, remuneração estratégica e motivações para dar lastro ao estudo.

\subsection{Remuneração}

A remuneração pode ser considerada um dos sistemas mais importantes e complexos da administração de Recursos Humanos, pois procura estimular a busca por desempenhos cada vez melhores, como também procura alinhar os comportamentos dos indivíduos com os objetivos estratégicos das organizações (Krauter, 2013). Conforme Marquart, Lunkes e Rosa (2012) a remuneração é basicamente constituída de duas partes principais, o salário base ou fixo e o salário variável, entretanto, segundo Beuren, Kaveski e Rigo (2014) os sistemas de remuneração vêm assumindo diversas formas e adquirindo uma forma mais ampla, considerando outros fatores além dos financeiros, neste sentido a remuneração pode ser dividida em duas perspectivas, conforme destacado na Figura n. 1.

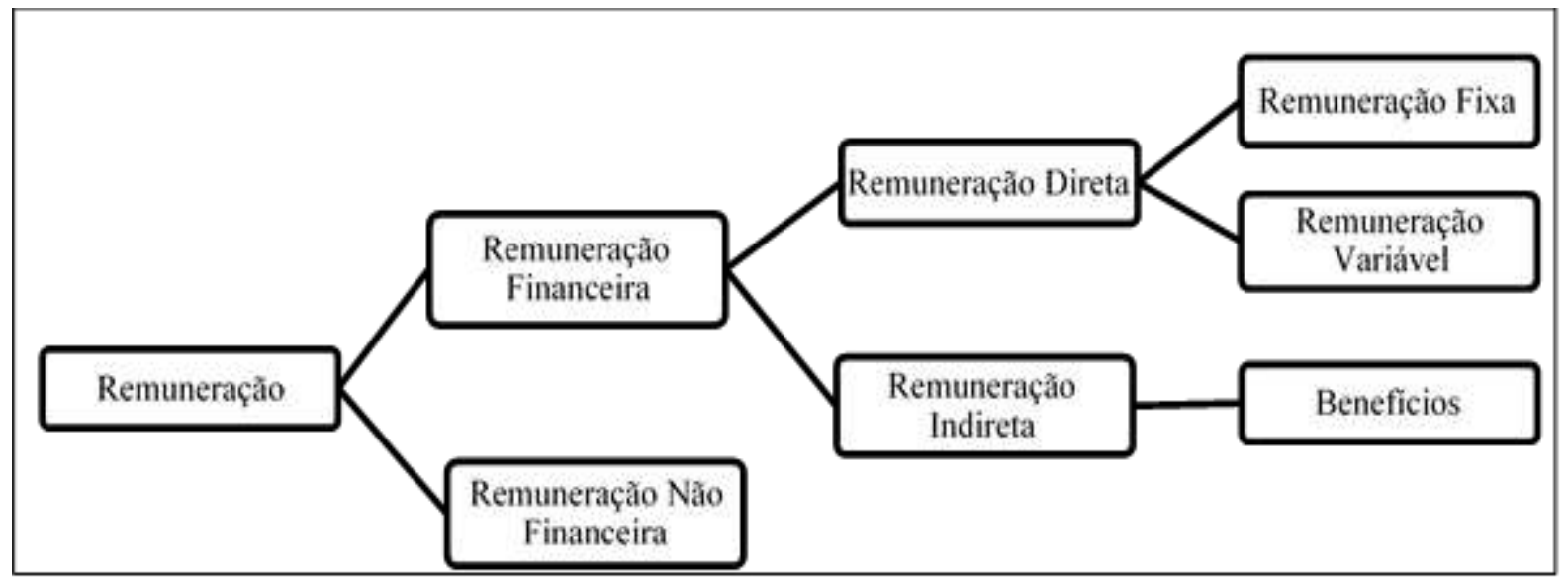

Figura 1. Formas de Remuneração

Fonte: Adaptado de Krauter (2009)

Considerando a estrutura apresentada na Figura n. 1, a remuneração financeira é a compensação econômica de um trabalho realizado. Já a remuneração não financeira, está associada a recompensas sobre os aspectos relacionados à carreira e ao desenvolvimento pessoal e profissional dos indivíduos. Isto é, fatores que melhorem as relações de trabalho, a participação, a inclusão e a confiança dos indivíduos (Chiang, \& Birtch, 2012). Conforme Krauter $(2009,2013)$ a remuneração financeira é a recompensa, na forma de reembolso econômico ou financeiro, de um trabalho realizado, que é dividida em direta e indireta.

A remuneração direta é dividida em duas outras formas, a remuneração fixa e variável, sendo que a fixa é norteada como o desembolso em forma de dinheiro que foi acordado inicialmente, entre a empresa e o colaborador, pago regularmente pelo trabalho desenvolvido, já a remuneração variável é o montante recebido em detrimento da realização de metas estipuladas e acordadas entre o indivíduo e a organização (Krauter, 2009, 2013).

Por fim, as remunerações não financeiras são incorporadas nas organizações, como aspectos relacionados à carreira e ao desenvolvimento pessoal dos colaboradores, oportunizando a perspectiva de 
crescimento profissional, o que é muito valorizado pelos indivíduos, com treinamentos e a educação, considerados aspectos fundamentais para promover o desenvolvimento pessoal e profissional dos agentes (Krauter, 2013). Em seguida, são apresentadas as definições e os tipos de remuneração estratégica.

\subsection{Remuneração Estratégica}

A remuneração estratégica surge dentro das organizações como uma nova abordagem de gestão empresarial, que tem como principal objetivo instigar a eficiência e a eficácia de remunerar os colaboradores, em função de resultados positivos (Brandão et al., 2012).

Nesse sentido, enquanto o sistema tradicional remunera os indivíduos somente pelas exigências associadas ao cargo, à remuneração estratégica procura beneficiar os colaboradores, que contribuem de alguma forma, para a maximização dos resultados das organizações, por meio do diferencial competitivo da mesma (Gheno, \& Berlitz, 2011). Assim, segundo os autores, a remuneração estratégica busca recompensar os indivíduos que, dentro de uma empresa, se destacam dos demais em um determinado tempo, tendo como base de avaliação três fatores principais, o conhecimento, habilidades e atitudes.

Desse modo, a adoção de um sistema de remuneração estratégica tem como um ponto relevante, 0 fato de não fixar os salários dos colaboradores de forma genérica, mas utilizar e atribuir métodos estratégicos, atrelados aos benefícios de retribuição conforme a contribuição do colaborador para à organização. Com isso, assegura um sistema de remuneração mais flexível, tornando a empresa mais competitiva e com profissionais qualificados, na medida em que os interesses relativos aos profissionais e as empresas poderão estar alinhados (Chiang, \& Birtch, 2012).

Machado e Beuren (2014) explicam que há diversos mecanismos pelos quais a política de remuneração pode oferecer um valor maior de incentivos, incluindo bônus anuais, acréscimos salariais baseados em desempenho, benefícios diversos (seguro de vida, plano de aposentadoria complementar, entre outros).

Além disso, a remuneração estratégica distribui-se em cinco grupos, classificados em um único sistema de remuneração: remuneração da responsabilidade ou funcional, remuneração do conhecimento ou Know-how, salário indireto ou benefícios, previdência complementar e remuneração variável (Marquart et al., 2012). A remuneração por responsabilidade, procura valorizar o papel desempenhado pelo colaborador na organização, considerando aspectos importantes, como a representatividade, a missão, a responsabilidade, e o relacionamento com fornecedores e clientes internos e externos, sendo totalmente independente dos resultados (Marquart et al., 2012).

Já a remuneração Know-How ou conhecimento leva em consideração os conhecimentos, habilidades e competências particulares, juntamente com suas características individuais. $E$, por conseguinte, a remuneração por resultados está ligada a indicadores relacionados ao negócio, a estratégia e ao mercado, estabelecidos e mensurados por resultados quantitativos, qualitativos e estratégicos, variando de acordo com o resultado alcançado pela organização (Marquart et al., 2012). 


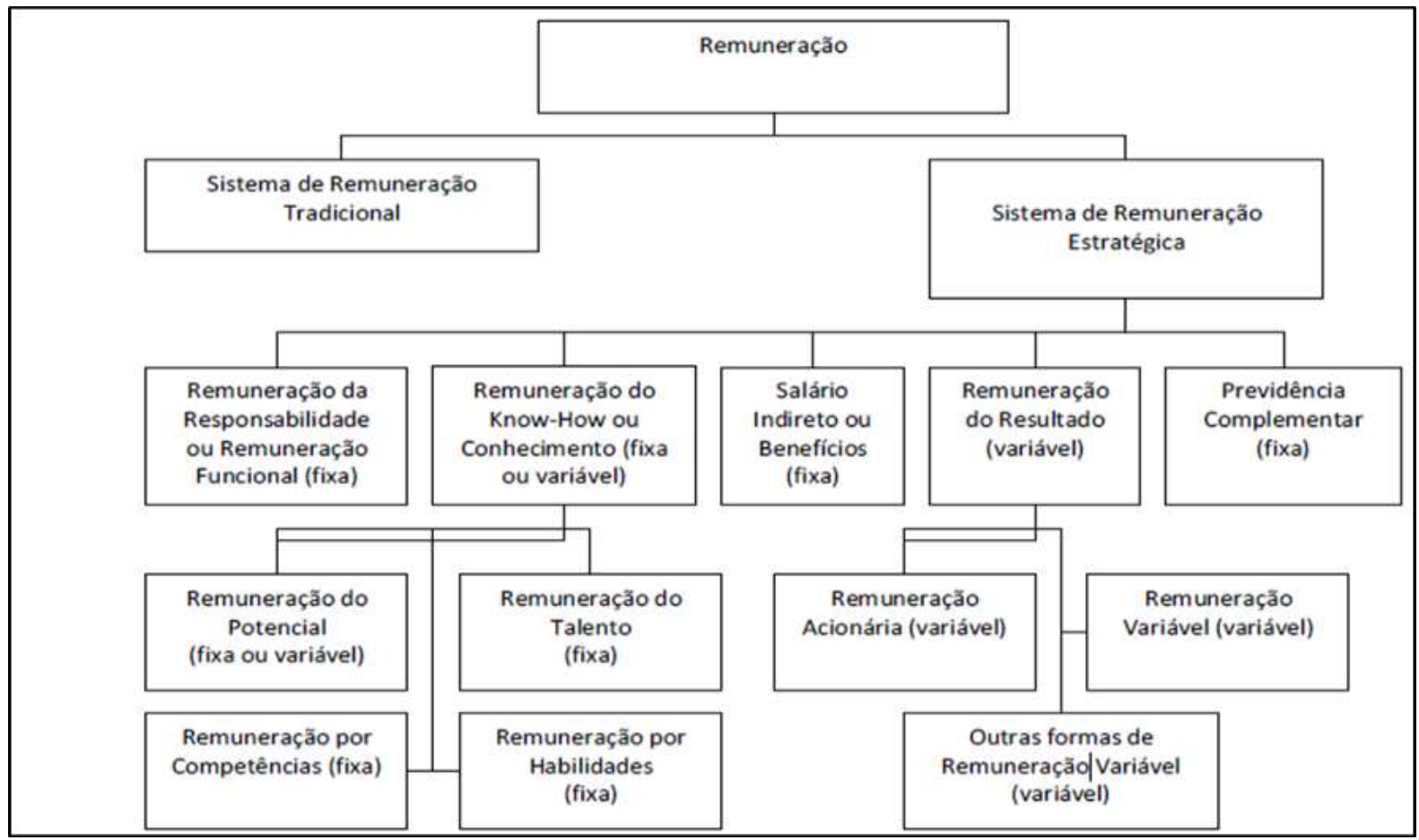

Figura 2. Tipos de Remuneração Estratégica

Fonte: Adaptado de Wood J r. e Picarelli Filho (2004); Xavier, Silva e Nakahara (1999)

Com relação ao cálculo da remuneração estratégica, pode ser baseado nas metas do departamento, da unidade e/ou dos empregados, entre outros critérios, assim cada organização determina aquilo que considera preponderante ou crítico para atingir. Consequentemente, atrelar a remuneração aos objetivos estratégicos da organização é uma forma de gerar melhores resultados, pois provoca em cada pessoa um comprometimento com as estratégias da empresa (Marquart et al., 2012).

No tocante à remuneração estratégica, Beuren, Silva e Mazzioni (2014) apontam a necessidade primordial do alinhamento de interesses, isto é, entre os indivíduos e as organizações. Além disso, esse alinhamento de interesses deve estar pautado sobre um sistema de monitoramento (pelo qual o principal analisa e estabelece as limitações sobre os gestores) e a compensação (por meio de contrato com base nos resultados). Cabe destacar ainda, que o alinhamento desses interesses entre as partes é adequado na medida em que seja possível verificar uma relação positiva entre a remuneração dos executivos e o resultado das organizações (Beuren, Silva, \& Mazzioni, 2014).

Em se tratando da carreira, as ações das organizações englobam mecanismos de planejamento e acompanhamento de carreira, de recolocação em caso de demissão, de recrutamento interno e de preparação para a aposentadoria (Krauter, 2013). Diante disso, a remuneração estratégica é formada por: remuneração acionária, remuneração por habilidades, remuneração por competências, participação nos lucros, remuneração por resultados, distribuição de ganhos, planos de bonificação e benefícios sociais (Gheno \& Berlitz, 2011).

\begin{tabular}{|l|l|}
\hline $\begin{array}{l}\text { Remuneração } \\
\text { Acionária }\end{array}$ & $\begin{array}{l}\text { Uma das formas mais complexas de remuneração, mas que se bem projetada, pode } \\
\text { gerar para a empresa e seus colaboradores, grandes benefícios a médio e longo } \\
\text { prazo. Consiste na distribuição ou venda de ações para uma parcela restrita dos } \\
\text { colaboradores, geralmente escalados nos altos graus e responsáveis pelas decisões } \\
\text { estratégicas da organização, cabendo ao empregado desfrutar das vantagens } \\
\text { monetárias e dividendos, além do direito à valorização dos mesmos. }\end{array}$ \\
\hline $\begin{array}{l}\text { Considerada uma forma alternativa de remuneraça, seu foco está no indivíduo e não } \\
\text { no cargo, para justificar as diferenças salariais, permitindo o constante }\end{array}$ \\
$\begin{array}{l}\text { Remuneração por } \\
\text { desenvolvimento profissional, uma vez que este tipo de remuneração procura } \\
\text { Habilidades }\end{array}$ & \begin{tabular}{l} 
reconhecer a capacitação dos profissionais. No entanto cabe à organização a definir \\
\hline
\end{tabular}
\end{tabular}




\begin{tabular}{|c|c|}
\hline & $\begin{array}{l}\text { quais habilidades o profissional deve desenvolver, estabelecendo, os passos } \\
\text { necessários para sua evolução, além de formas e regras para o treinamento e a } \\
\text { comprovação. }\end{array}$ \\
\hline $\begin{array}{l}\text { Remuneração por } \\
\text { Competências }\end{array}$ & $\begin{array}{l}\text { Este tipo de remuneração identifica e avalia o desenvolvimento e reconhecimento de } \\
\text { habilidades e conhecimentos que os profissionais devem ter para desenvolver suas } \\
\text { tarefas. A remuneração por competência, ao contrário da remuneração por } \\
\text { habilidades, está voltada para profissionais que ocupam cargo de liderança, controle, } \\
\text { planejamento e responsabilidade de resultados. }\end{array}$ \\
\hline $\begin{array}{l}\text { Participação nos } \\
\text { lucros }\end{array}$ & $\begin{array}{l}\text { O recebimento de tal gratificação por parte dos colaboradores, está diretamente } \\
\text { ligado aos resultados alcançados pela organização, levando em consideração o lucro } \\
\text { atingido. Esta remuneração é eficaz em empresas cuja remuneração fixa está abaixo } \\
\text { do praticado pelo mercado e cujo desejo seja a flexibilidade de pagamento, com } \\
\text { valores acima do mercado nos anos bons, sem ter a necessidade de cortar pessoal ou } \\
\text { custos durante anos difíceis, permitindo contemplar com uma parcela em espécie } \\
\text { todos os colaboradores da empresa. }\end{array}$ \\
\hline $\begin{array}{l}\text { Remuneração por } \\
\text { Resultados }\end{array}$ & $\begin{array}{l}\text { Este tipo de remuneração vincula o desempenho do funcionário à produtividade e à } \\
\text { qualidade dos resultados organizacionais, incentivando os colaboradores ao trabalho } \\
\text { e ao alcance das metas estabelecidas. A remuneração por resultados permite } \\
\text { impulsionar as metas financeiras, além da possibilidade de ser aplicada para alcançar } \\
\text { valores mais relevantes com relação à produtividade, satisfação do cliente, serviços e } \\
\text { qualidade. }\end{array}$ \\
\hline $\begin{array}{l}\text { Distribuição de } \\
\text { Ganhos }\end{array}$ & $\begin{array}{l}\text { Está relacionado a metas específicas de produtividade, com a melhoria da qualidade, } \\
\text { a reduçãa dos custos, entre outros, é comum nos níveis inferiores e intermediários da } \\
\text { pirâmide organizacional, procurando remunerar a criatividade e capacidade das } \\
\text { pessoas em sugerir ações inovadoras, além de resolver problemas. }\end{array}$ \\
\hline $\begin{array}{l}\text { Plano } \\
\text { Bonificação }\end{array}$ & $\begin{array}{l}\text { São valores pagos periodicamente, aos colaboradores, pelo desempenho positivo de } \\
\text { indicadores, além do lucro, como a produtividade e o aumento na participação do } \\
\text { mercado. Este tipo de bônus não costuma fazer parte do salário. }\end{array}$ \\
\hline $\begin{array}{l}\text { Plano de } \\
\text { Benefícios Sociais }\end{array}$ & $\begin{array}{l}\text { São benefícios oferecidos aos colaboradores com base na satisfação de suas } \\
\text { necessidades pessoais, sendo considerados fundamentais para mantê-los satisfeitos } \\
\text { com a organização, e são oferecidos em formas de pacotes que variam de acordo com } \\
\text { o nível hierárquico do colaborador. }\end{array}$ \\
\hline
\end{tabular}

\section{Quadro 1. Conceitos das formas de remuneração}

Fonte: Adaptado de Gheno e Berlitz (2011)

No Quadro n. 1, são apresentados alguns conceitos de remuneração utilizados pelas organizações, considerados como meios de incentivar os colaboradores a ter uma maior participação nas atividades da empresa, oferecendo oportunidade de desenvolvimento dos colaboradores, e estabilidade dentro da organização (Cardozo, Nascimento, \& Gasparetto, 2011). A seguir, são tratados os fatores relacionados à motivação dos colaboradores.

\subsection{Motivação}

A motivação é composta por duas partes. A primeira refere-se os desejos individuais e as expectativas de alcançá-las. Já a segunda, o que motiva é o atingir de uma meta, isto pode levar a uma motivação para novos desafios, dado que são as circunstâncias do próprio trabalho que funcionam como fatores motivadores. Cabe ressaltar que, o homem busca descobrir coisas, realizar-se, atualizar-se, progredir e agregar coisas a sua existência, e as necessidades humanas estão dispostas em níveis de importância e influência (Herzberg, Mausner, \& Snyderman,1957; Vroom, 1964; Maslow, 1970).

Dessa maneira, na perspectiva tratada pelos autores Anthony e Govindarajan $(2012$, p. 513) "a chave para se motivar as pessoas a se comportar de uma maneira que ajude a alcançar as metas da organização está no modo como que os incentivos da organização se relacionam com as metas individuais". Ademais, de acordo com os autores, os indivíduos podem ser influenciados por incentivos positivos e negativos. Os incentivos positivos, ou recompensas, são resultados que procuram aumentar a satisfação dos indivíduos e, os negativos, 
servem como punição, reduzindo a motivação e a satisfação desses indivíduos (Anthony, \& Govindarajan, 2012).

Com isso, os sistemas de incentivos ou sistemas de remuneração, podem contribuir de forma positiva para eficácia organizacional, transformando-se em vantagem competitiva, se utilizada de forma alinhada aos interesses dos indivíduos e organizações. Esse tratamento deve ser dado, desde que as organizações não utilizem os sistemas de recompensa apenas para minimizar as insatisfações, mas adote esse sistema para motivar os colaboradores a desempenharem suas funções com melhor efetividade possível e, se preocupem com o sucesso da organização (Beuren, Kaveski, \& Rigo, 2014).

Esses incentivos podem ser financeiros, psicológicos e sociais. Os incentivos financeiros incluem aumentos de salários, gratificações, benéficos e prerrogativas (automóveis, viagens de férias, títulos de clubes). Já os incentivos psicológicos e sociais incluem possibilidades de promoção, aumentos de responsabilidade, aumento de autonomia, melhor localização e reconhecimento (troféus, participação em programas de executivos) (Anthony \& Govindarajan, 2012).

Neste sentido, Aguiar et al. (2012), apontam que os sistemas de incentivo gerencial podem contribuir para a conquista dos objetivos organizacionais, onde benefícios financeiros podem induzir a comportamentos, garantindo determinado nível de desempenho, esperado pela empresa. A combinação dos resultados individuais e organizacionais, quando utilizados estruturas de remuneração mais flexíveis, tendem a possuir relação com as perspectivas pessoais e profissionais, e organizações que não reconhecem a capacidade contributiva dos colaborado res, acabam por provocar a desmotivação e o descontentamento dos profissionais (Nascimento, Franco, \& Cherobim, 2012).

Assim, segundo os autores Nascimento, Franco e Cherobim (2012) a remuneração passa a assumir um papel muito importante nas organizações, pois tem como objetivo reconhecer a contribuição e 0 valor agregado dos profissionais, por meio da diferenciação dos diversos níveis de resultados. Na próxima sessão, é apresentada a metodologia utilizada no desenvolvimento da pesquisa.

\section{METODOLOGIA}

Esta pesquisa tem como objetivo analisar a percepção dos colaboradores de instituições financeiras públicas e privadas sobre a remuneração estratégica. A metodologia utilizada no estudo classifica-se, quanto aos objetivos, descritiva, pois procura descrever as características de determinada população ou fenômeno (Hair J r., Babin, Money, \& Samouel, 2005); quanto aos procedimentos, levantamento ou survey (Babbie, 1999) uma vez que se procura, por meio da aplicação de um questionário, coletar informações dos integrantes do universo a ser pesquisado; e quanto a abordagem do problema, quantitativa, caracterizada pelo emprego de instrumentos estatísticas (Richardson et. al, 2009). Conforme Hair Jr. et al. (2010), ao utilizar da abordagem quantitativa em procedimentos descritivos, nos quais se procura descobrir e classificar a relação entre variáveis, busca-se a validação de fatos, o encontro de estimativas e relacionamentos e a testagem de hipóteses.

Os dados foram coletados por meio da aplicação de questionário no período de Maio a u ulho de 2017 com colaboradores dos bancos públicos, privados e cooperativas de crédito em Cascavel - PR. Os questionários foram enviados via formulário eletrônico e também entregues pesso almente nas agências e coletados nos dias seguintes. Diante disso, perfez a amostra o total de 154 respondentes.

A análise dos dados deu-se por meio de análises multivariada, com auxílio de um software estatístico IBM SPSS 21. Utilizando-se da técnica de análise fatorial exploratória, técnica que permite sintetizar as relações observadas, buscando identificar fatores comuns. E para análise da consistência interna, foi utilizado o Alfa de Cronbach (Fávero et al., 2009). Assim, na próxima seção, são apresentadas e discutidas as análises dos dados.

\section{ANÁLISE DOS DADOS}

Neste tópico foi abordado os dados descritivos sobre os tipos de remuneração, e também, a análise multivariada referente à análise fatorial e Alfa de Cronbach. 


\subsection{Achados sobre remuneração}

A remuneração é tida como a característica que define o trabalho assalariado, utilizado como ferramenta de troca pela empresa, pelo serviço do empregado, em um determinado tempo, compreendendo as formas de retorno financeiro e benefícios recebidos pelos empregados em relação de trabalho (Marquart et al., 2012).

\begin{tabular}{l|c|c}
\hline \multicolumn{1}{c|}{ Tipo de Remuneração } & Frequência & $\%$ \\
\hline Benefícios adicionais (além dos estabelecidos em lei) & 22 & $14.28 \%$ \\
\hline Bolsa Auxílio & 1 & $0.64 \%$ \\
\hline Bônus e gratificações & 32 & $20.77 \%$ \\
\hline Comissões & 19 & $12.33 \%$ \\
\hline Função gratificada & 1 & $0.64 \%$ \\
\hline Participação Acionária & 1 & $0.64 \%$ \\
\hline Participação nos lucros e resultados & 39 & $25.32 \%$ \\
\hline Remuneração por competências & 2 & $1.27 \%$ \\
\hline Remuneração por resultados (alcance de metas) & 16 & $10.38 \%$ \\
\hline Salário-base & 44 & $28.57 \%$ \\
\hline
\end{tabular}

Tabela 1. Tipos de remuneração

Fonte: Dados da Pesquisa (2017)

Dentre as opções oferecidas, o salário-base foi o mais citado pelos profissionais, representando $28.57 \%$ dos respondentes, porque segundo Wood Jr. e Picarelli Filho (2004) a remuneração por meio de salários-base permite uma sensação de equidade externa, permitindo aos colaboradores comparar seus salários com os praticados no mercado, aumentando a percepção de justiça, e ainda colaborando para que a organização estabeleça diretrizes adequadas para atrair e reter os colaboradores.

A participação nos lucros e resultados é recebida por 25,32\% dos bancários, o que representa 39 respondentes, estando esta remuneração diretamente ligada aos resultados alcançados pela organização, levando-se em conta o lucro atingido, permitindo uma flexibilidade no pagamento, e contemplando uma parcela dos colaboradores da empresa, e destinados a aumentar a produtividade ou diminuir os custos de pessoal. Conforme ressalta Gheno e Berlitz (2011) a participação nos lucros e resultados buscam motivar os colaboradores, tornando-os mais comprometidos com o desempenho financeiro da instituição. No entanto, este sistema de remuneração sofre problema quanto à vinculação do desempenho e os esforços dos indivíduos, assim, pode-se causar uma sensação de injustiça dentre os colaboradores, visto que este pode não perceber essa retribuição como consequência do trabalho prestado.

Os bônus e gratificações são recebidos por 32 respondentes, $20,77 \%$ das observações. Percebe-se que são poucos os colaboradores que recebem este tipo de remuneração, pois este sistema de recompensa possui como principal característica, o fato de ser voltado para a direção da empresa e possuir poucos participantes, sendo seletivo (Gheno \& Berlitz, 2011).

Benefícios adicionais são recebidos por 14,28\% dos respondentes. Esta remuneração abrange outras formas de recompensa, envolvendo benefícios e outras vantagens, além dos estabelecidos por lei, e que as entidades concedem aos colaboradores, variando de acordo com os níveis hierárquicos (Nichele, Stefano \& Raifur, 2015).

As comissões são recebidas por $12,33 \%$ dos respondentes, já 10,38\% dos indivíduos recebem a remuneração por resultados (alcance de metas). Estas duas formas de remuneração, procuram recompensar os colaboradores com base no desempenho do funcionário, vinculando à produtividade e à qualidade dos resultados, procurando incentivar os empregados ao trabalho e ao alcance de metas (Gheno \& Berlitz, 2011).

Para Robbins, Judge e Sobral, F. (2011), colaboradores satisfeitos tendem a falar bem da empresa, a contribuir com os colegas e a excederem as expectativas com relação ao trabalho, podendo também superar suas atribuições regulares pelo anseio de retribuir as expectativas positivas, mas são diversos os motivos que 
levam os colaboradores a se manterem motivados e apresentarem desempenho no trabalho, dentre os quais os destacados na Tabela n. 2.

\begin{tabular}{|c|c|c|c|c|c|}
\hline Motivação & $\begin{array}{c}\text { Não é } \\
\text { important } \\
\text { e }\end{array}$ & $\begin{array}{l}\text { Pouco } \\
\text { importante }\end{array}$ & Indiferente & Importante & $\begin{array}{l}\text { Muito } \\
\text { importante }\end{array}$ \\
\hline Salários & & & $4.26 \%$ & $27.66 \%$ & $68.09 \%$ \\
\hline Gratificações & & $2.13 \%$ & $10.64 \%$ & $29.79 \%$ & $57.45 \%$ \\
\hline Benefícios & $2.13 \%$ & $2.13 \%$ & $12.77 \%$ & $23.40 \%$ & $59.57 \%$ \\
\hline $\begin{array}{l}\text { Prerrogativas (automóveis, viagens } \\
\text { de férias, títulos de clubes) }\end{array}$ & $8.51 \%$ & $4.26 \%$ & $23.40 \%$ & $31.91 \%$ & $31.91 \%$ \\
\hline Recompensas recebidas & $4.26 \%$ & & $10.64 \%$ & $29.79 \%$ & $55.32 \%$ \\
\hline $\begin{array}{l}\text { Tratamento justo (contribuição x } \\
\text { recompensa) }\end{array}$ & $2.13 \%$ & $2.13 \%$ & $2.13 \%$ & $21.28 \%$ & $72.34 \%$ \\
\hline Possibilidades de promoção & & $4.26 \%$ & $2.13 \%$ & $29.79 \%$ & $63.83 \%$ \\
\hline Aumentos de responsabilidade & $4.26 \%$ & $2.13 \%$ & $12.77 \%$ & $34.04 \%$ & $46.81 \%$ \\
\hline $\begin{array}{l}\text { Autonomia na realização das } \\
\text { tarefas }\end{array}$ & $2.13 \%$ & $4.26 \%$ & & $38.30 \%$ & $55.32 \%$ \\
\hline Melhor localização & $4.26 \%$ & $2.13 \%$ & $14.89 \%$ & $42.55 \%$ & $36.17 \%$ \\
\hline $\begin{array}{l}\text { Reconhecimento (troféus, } \\
\text { participação em programas de } \\
\text { executivos) }\end{array}$ & $10.64 \%$ & $6.38 \%$ & $25.53 \%$ & $31.91 \%$ & $25.53 \%$ \\
\hline Status/valorização social & $4.26 \%$ & $8.51 \%$ & $27.66 \%$ & $34.04 \%$ & $25.53 \%$ \\
\hline Aprendizado & $2.13 \%$ & & $8.51 \%$ & $31.91 \%$ & $57.45 \%$ \\
\hline $\begin{array}{l}\text { Jornada compatível com as } \\
\text { necessidades de tempo livre }\end{array}$ & $2.13 \%$ & & $17.02 \%$ & $34.04 \%$ & $46.81 \%$ \\
\hline $\begin{array}{l}\text { Oportunidade de realizar um } \\
\text { trabalho relevante e significativo }\end{array}$ & $2.13 \%$ & $2.13 \%$ & $8.51 \%$ & $34.04 \%$ & $53.19 \%$ \\
\hline Feedback quanto ao seu progresso & $2.13 \%$ & & $6.38 \%$ & $42.55 \%$ & $48.94 \%$ \\
\hline Resultado desafiador & $2.13 \%$ & & $12.77 \%$ & $38.30 \%$ & $46.81 \%$ \\
\hline
\end{tabular}

Tabela 2. Fatores motivacionais

Fonte: Dados da Pesquisa (2017)

Quando questionados sobre os fatores motivacionais que os levam a produzir mais, a respeito dos itens descritos na Tabela n. 2, os resultados apontam que todos os itens financeiro são tidos como mais importantes na percepção dos respondentes e são levados em consideração no momento de melhorar seu desempenho e produzir mais, no entanto o tratamento justo foi considerado o mais importante, uma vez que $72.34 \%$ dos respondentes o consideram muito importante, seguidos dos salários, possibilidades de promoção e benefícios adicionais, verificando-se assim que tanto os incentivos financeiros quantos incentivos psicológicos e sociais são importantes para os colaboradores, esses resultados são semelhantes aos de estudos de (Murphy, 1985; Watson, 1994; Appelbaum e Kamal, 2000; Rayton, 2003; Bebchuk e Grinstein, 2005; Moers, 2006; Fong, Misangyi e Tosi, 2010; Vlachos, 2011; Aktar, Sachu e Ali, 2012; Chiang e Birtch, 2012; Erbasi e Arat, 2012) que destacam o efeito dos incentivos financeiros e não financeiros no crescimento das empresas.

Embora o tratamento justo tenha sido considerado o mais importante dentre os fatores motivacionais, isso remete a uma reflexão acerca das práticas de remuneração entre gênero, ou ainda, diferenças salariais entre pessoas que desenvolvem a mesma atividade. Diferentemente o status social e 0 
reconhecimento são observados como menos importantes, talvez em face a individualidade proporcionada por tais fatores motivacionais.

Cardozo et al. (2011) destacam que a remuneração estratégica faz parte de uma nova realidade das empresas, passando a considerar to do o contexto organizacional e como a empresa quer ser no futuro, assim a remuneração assume um papel decisivo neste cenário, pois serve como ferramenta para manter os colaboradores comprometidos com o desempenho e objetivos da organização. Marquart et al. (2012) considera que a remuneração estratégica deve levar em consideração os desejos dos colaboradores, suas expectativas e suas características individuais.

\subsection{Percepção dos Colaboradores}

Nesta seção foram abordados desde os testes de adequação da amostra, consistência interna por meio do Alfa de Cronbach, e a análise fatorial.

Os testes de adequação da amostra para a análise fatorial são os testes de Kaiser-Meyer-Olkin - KMO e $o$ teste de Bartlett. Assim, no teste KMO os valores até 0,5 são considerados incoerentes para a análise em questão, de 0,5 a 0,6 são considerados medíocres, entre 0,6 a 0,8 considera-se razoáveis e, acima de 0,8 os dados detêm boa qualidade (Fávero, Belfiore, Silva \& Chan, 2009). Já o teste de Bartlett verifica a existência de uma matriz identidade, aonde os dados apresentam correlação com as outras variáveis em $\mathrm{r}-1$. Com isso, no teste de Bartlett parte do princípio da hipótese nula de correlação, logo o p valor deve ser menor que a significância delimitada. Já o Alfa de Cronbach, analisa a confiabilidade do constructo aplicado, quanto mais próximo de 1 maior confiabilidade interna possui o instrumento (Hair Jr. et al., 2005).

\begin{tabular}{|ll|}
\hline Medida Kaiser-Meyer-Olkin de adequação de amostragem. &, 829 \\
\hline Teste de esfericidade de Bartlett &, 000 \\
\hline Alfa de Cronbach &, 907 \\
\hline
\end{tabular}

Quadro 2. Teste de adequação e confiabilidade interna das instituições públicas Fonte: Dados da pesquisa (2017).

O resultado do teste de KMO para o construto das instituições públicas, foi de 0,829 , portanto a adequação do modelo para a análise fatorial é adequada e de boa qualidade (Fávero et al., 2009). Quanto ao teste de esfericidade de Bartlett, o p valor foi menor que 1\%, logo, confirma a hipótese nula de correlação entre as variáveis em $r-1$, e assim, os dados são adequados para análise fatorial. 0 valor de 0,907 para o Alfa de Cronbach demonstrou alta confiabilidade interna (Hair J r. et al., 2005). Dessa forma, os dados coletados são adequados para a análise fatorial proposta. 0 Quadro n. 3 descreve os testes de adequação e confiabilidade.

\begin{tabular}{|lc|}
\hline Medida Kaiser-Meyer-Olkin de adequação de amostragem. &, 817 \\
\hline Teste de esfericidade de Bartlett &, 000 \\
\hline Alfa de Cronbach &, 867 \\
\hline
\end{tabular}

Quadro 3. Teste de adequação e confiabilidade interna das instituições privadas Fonte: Dados da pesquisa (2017).

Para as instituições privadas o teste de KMO também se mostrou adequado e de boa qualidade para a análise fatorial, pois o seu valor foi de 0,817 (Fávero et al., 2009). Assim como para as instituições públicas, 0 teste de Bartlett também comprovou a inexistência de autocorrelação, pois o p valor foi abaixo de 1\%. Eo Alfa de Cronbach, foi de 0,867 , demonstrando alta confiabilidade interna. Logo, os dados coletados referentes às instituições privadas também se adequam para a análise fatorial.

Foram encontrados 4 fatores para explicar a percepção dos colaboradores das instituições financeiras privadas, sendo eles denominados como: os Incentivos psicológicos e sociais (componente 1); Recompensas (componente 2); Status (componente 3); e Cargos e Salários (componente 4). 0 método de extração utilizado foi método de análise do componente principal e quanto ao método de rotação, foi realizado pelo método 
Varimax com normalização de Kaiser. A rotação dos fatores visa aprimorar a interpretação, pois no método eleva-se os valores mais altos e reduz os valores mais baixos, e ainda, é considerado significativo os valores acima de 0,5 (Sharma, 1996). 0 Quadro n. 4 mostra a matriz componente rotativa pelo método Varimax com normalização de Kaiser das instituições financeiras privadas.

\begin{tabular}{|c|c|c|c|c|}
\hline Afirmativas & $\begin{array}{c}\text { Componente } \\
1\end{array}$ & $\begin{array}{c}\text { Componente } \\
2\end{array}$ & $\begin{array}{c}\text { Componente } \\
3\end{array}$ & $\begin{array}{c}\text { Componente } \\
4\end{array}$ \\
\hline $\begin{array}{l}\text { Salários } \\
\text { Gratificações } \\
\text { Benefícios } \\
\text { Prerrogativas (automóveis, viagens de } \\
\text { férias, títulos de clubes) } \\
\text { Recompensas recebidas } \\
\text { Tratamento justo (contribuição x } \\
\text { recompensa) } \\
\text { Possibilidades de promoção } \\
\text { Aumentos de responsabilidade } \\
\text { Autonomia na realização das tarefas } \\
\text { Melhor localização } \\
\text { Reconhecimento (troféus, participação } \\
\text { em programas de executivos) } \\
\text { Status/valorização social } \\
\text { Aprendizado } \\
\text { Jornada compatível com as } \\
\text { necessidades de tempo livre } \\
\text { Oportunidade de realizar um trabalho } \\
\text { relevante e significativo } \\
\text { Feedbackquanto ao seu progresso } \\
\text { Resultado desafiador }\end{array}$ & $\begin{array}{l}\text {,740 } \\
, 580 \\
, 764 \\
, 830 \\
, 733\end{array}$ & $\begin{array}{l}\text {,748 } \\
\text { 826 } \\
\text {,740 }\end{array}$ & $\begin{array}{l}\text {,642 } \\
\text { 708 } \\
\text { 847 }\end{array}$ & $\begin{array}{l}\text {,764 } \\
610 \\
\text {,723 }\end{array}$ \\
\hline
\end{tabular}

Quadro 4. Matriz componente rotativa pelo método Varimax com normalização de Kaiser das instituições financeiras privadas.

Fonte: Dados da pesquisa (2017).

O componente denominado como remuneração indireta aborda desde os atributos como promoção, responsabilidade, autonomia, aprendizado, jornada compatível, até resultado desafiador. Dessa forma, esse componente demonstra a percepção dos colaboradores das instituições financeiras privadas referente aos incentivos psicológicos e sociais. Já o segundo componente, é percebido pelos colaboradores das instituições financeiras públicas por meio dos atributos relacionado a Recompensas, pois os atributos referem-se as recompensas versus tratamento justo. 0 terceiro componente, foi denominado como Prestígio Social devido aos atributos se evidenciar por meio de status, troféus, localização. E o quarto, refere-se à Remuneração direta, tais como salários, gratificações e benefícios.

Para as instituições públicas também foram encontrad os quatro componentes e, denominados como Status, Incentivos Psicológicos e Sociais, Cargos e Salários e Responsabilidades e Desafios, os componentes referentes às instituições públicas estão descritos no Quadro n. 5. 


\begin{tabular}{|c|c|c|c|c|}
\hline Afirmativas & $\begin{array}{c}\text { Componente } \\
1\end{array}$ & $\begin{array}{c}\text { Componente } \\
2\end{array}$ & $\begin{array}{c}\text { Componente } \\
\mathbf{3}\end{array}$ & $\begin{array}{c}\text { Componente } \\
4\end{array}$ \\
\hline Salários & & &, 576 & \\
\hline Gratificações & & & 654 & \\
\hline Benefícios & & & ,806 & \\
\hline $\begin{array}{l}\text { Prerrogativas (automóveis, viagens de } \\
\text { férias, títulos de clubes) }\end{array}$ & & & & \\
\hline Recompensas recebidas & ,795 & & & \\
\hline $\begin{array}{l}\text { Tratamento justo (contribuição } \mathrm{x} \\
\text { recompensa) }\end{array}$ & & 696 & & \\
\hline Possibilidades de promoção & & & ,607 & \\
\hline Aumentos de responsabilidade & & & & 705 \\
\hline Autonomia na realização das tarefas & & ,680 & & \\
\hline Melhor localização & ,775 & & & \\
\hline $\begin{array}{l}\text { Reconhecimento (troféus, participação } \\
\text { em programas de executivos) }\end{array}$ & ,729 & & & \\
\hline Status/valo rização social & 684 & & & \\
\hline Aprendizado & & ,623 & & \\
\hline $\begin{array}{l}\text { Jornada compatível com as } \\
\text { necessidades de tempo livre }\end{array}$ & & ,735 & & \\
\hline $\begin{array}{l}\text { Oportunidade de realizar um trabalho } \\
\text { relevante e significativo }\end{array}$ & & 678 & & \\
\hline Feedbackquanto ao seu progresso & &, 557 & & \\
\hline Resultado desafiador & & & & ,705 \\
\hline
\end{tabular}

Quadro 5. Matriz componente rotativa pelo método Varimax com normalização de Kaiser das instituições financeiras públicas.

Fonte: Dados da pesquisa (2017).

Para as instituições públicas, nota-se que o primeiro componente se refere ao Status, pois está atribuído desde as prerrogativas, reconhecimento e valorização social. Já o segundo, refere-se aos incentivos psicológicos e sociais e, estão atribuídos desde ao tratamento justo, autonomia, aprendizado, jornada flexível até ao feedback e resultado desafiador. Já o terceiro, refere-se à cargos e salários devido abordar o salário, gratificação, benefícios e possibilidade de promoção. 0 último componente aborda a Responsabilidade e os Desafios, assim denominado.

Conforme demonstrado na figura n. 3, para as instituições privadas a variância total explicada foi de $62,63 \%$. 0 fator que mais explica a percepção dos colaboradores é o componente referente aos Incentivos Psicológicos e Sociais, sendo $35,00 \%$ da variação total. As recompensas explicaram $12,53 \%$, assim sendo, é 0 segundo que mais explica. Já o componente referente ao Status, explicou 7,72\% da percepção. E com apenas $7,38 \%$, o componente referente aos cargos e salários foi o que menos explica, porém ainda assim, é um componente relevante. 


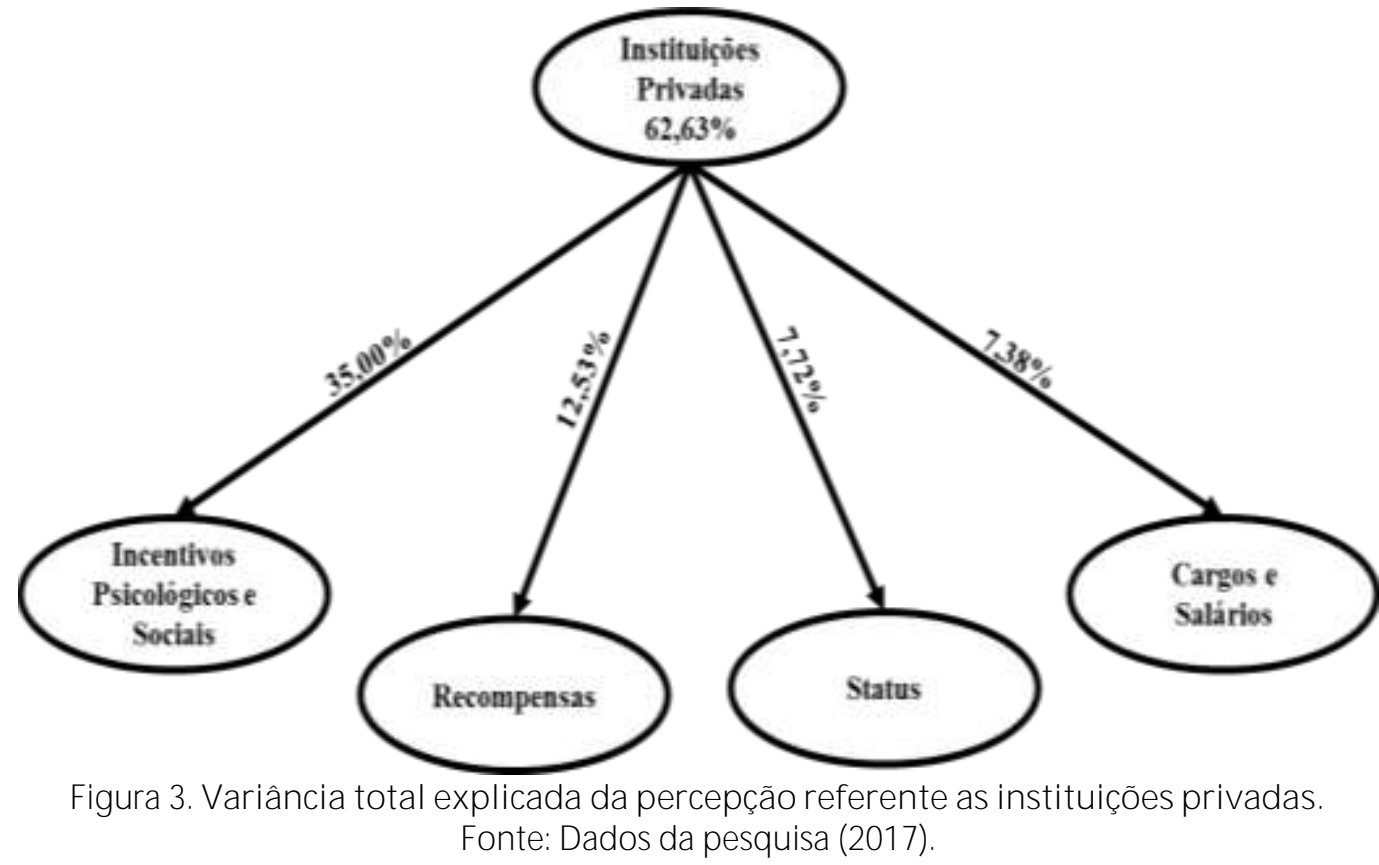

Os resultados evidenciados na Figura n. 3, remetem uma significância ao terceiro elemento da remuneração estratégica como proposto na definição dos autores Wood Júnior e Picarelli Filho (2004). Além disso, confirmam a importância dos benefícios e oportunidades propostas pelas organizações na busca de motivar os colaboradores, ideia conceituada por Gheno e Berlitz (2011). E ainda, nota-se a remuneração direta foi o componente que menos explica as percepções dos colaboradores das instituições financeiras privadas.

Para as instituições públicas a variância total explicada foi de $69,08 \%$. 0 fator que mais explica a percepção dos colaboradores é o componente referente aos Status, com 42,13\% da variação total. Os incentivos Psicológicos e Sociais por sua vez explicaram 12,87\%. Cargos e Salários, explica 7,41\% das variações, mesmo sendo o terceiro fator que mais explica, em comparação com as instituições públicas a diferença é de $3 \%$. 0 componente Responsabilidade e desafios explicou $6,68 \%$, porém, mesmo com o percentual menor entre os componentes, tem a sua importância para o total.

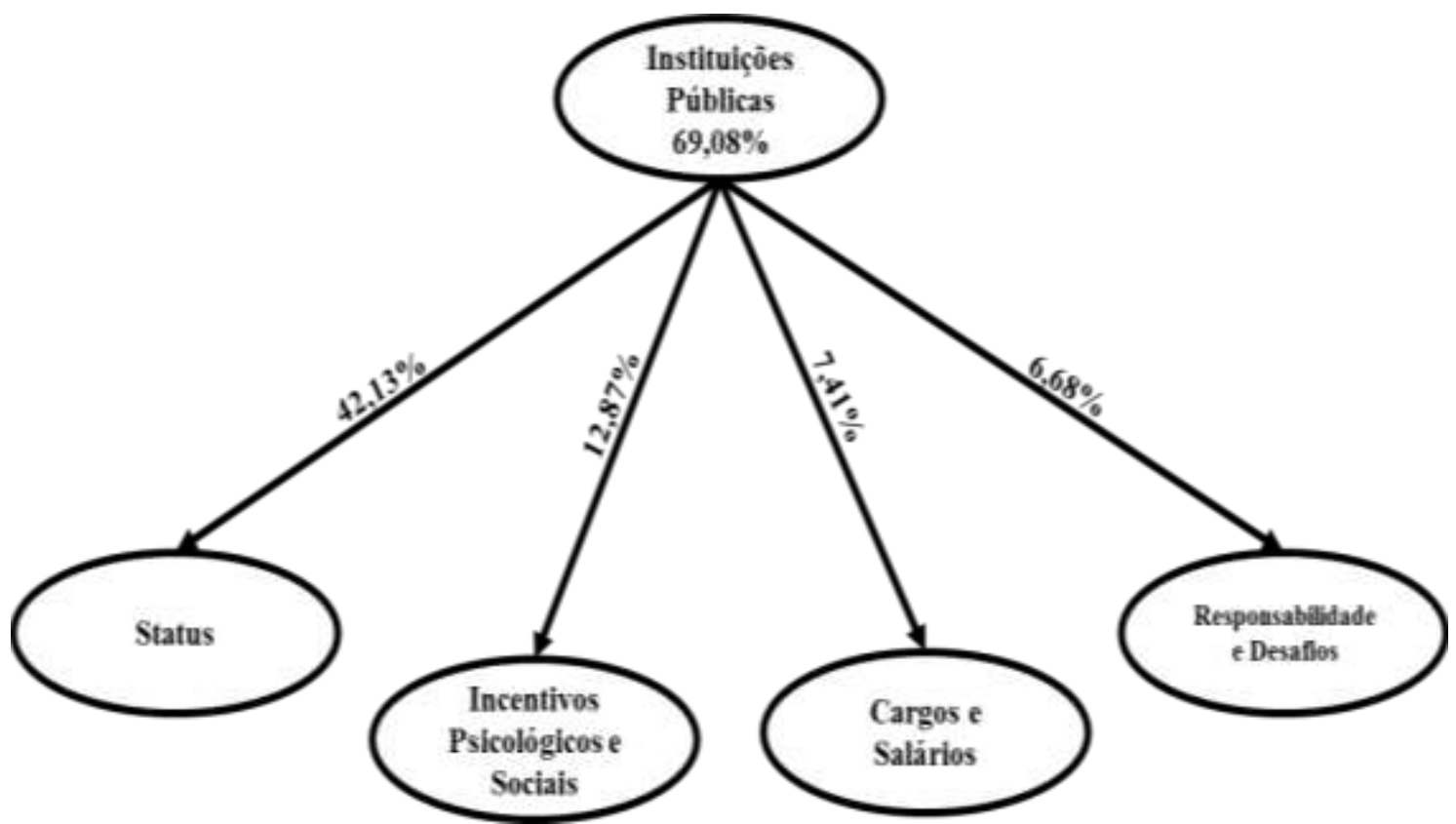

Figura 4. Variância total explicada da percepção referente as instituições públicas. Fonte: Dados da pesquisa (2017). 
Considerando os resultados da Figura n. 4, referentes a instituições públicas, é possível observar que o status precede os atributos relacionados aos pacotes de benefícios e oportunidades de crescimento e remuneração apontados por Gheno e Berlitz (2011) como fatores de maior atratividade. Entretanto, podem ser observados sob o enfoque dos autores Anthony e Govindarajan (2012), na perspectiva de que os incentivos estariam relacionados a fatores financeiros, psicológicos e sociais, contudo, devido à evidência da variância total explicada o status foi destacado em um componente separado, uma vez que os respondentes não percebem o status como um incentivo social ou psicológico.

Em comparação, na percepção dos colaboradores das instituições públicas com as instituições privadas, destacam-se como componentes que mais explicam a remuneração, o status para pública, e incentivos psicológicos e socais para privada. Pode-se elencar essa percepção devido ao fato dos colaboradores das instituições públicas terem a valorização social referente a aprovação de concursos públicos. Contudo, os Incentivos Psicológicos e Sociais ainda explicam a percepção desses colaboradores, mas com uma ênfase menor. Cargos e salários, em ambas instituições detêm uma variância muito próxima, apesar que no meio privado ser o último componente que explica a remuneração. Destaca-se também, a responsabilidade e desafios no âmbito público, com 6,68\% da variação total.

É possível por meio dessa comparação analisar as diferenças e semelhanças da percepção dos colaboradores das instituições financeiras públicas e privadas sobre a remuneração. Ficou evidente em ambas instituições, que o componente mais relacionado a remuneração direta não foi o mais reconhecido pelos colaboradores. Dessa forma, a importância dos demais tipos de remuneração se concretiza devido à percepção desses colaboradores. Mediante o exposto, por fim, na próxima seção, são apresentadas as considerações finais dessa pesquisa, com base nos resultados analisados e discutidos nessa seção.

\section{CONSIDERAÇÕES FINAIS}

O objetivo da pesquisa foi analisar a percepção dos colaboradores de instituições financeiras públicas e privadas sobre a remuneração estratégica. Nesse sentido, fundamentado nos resultados apresentados na sessão anterior, é possível verificar a convergência com a definição dos autores Marquart et al. (2012) ao considerar que a remuneração estratégica leva em consideração os desejos dos colaboradores, suas expectativas e suas características individuais. Assim, de acordo com os dados coletados e com as análises elaboradas, percebe-se que os salários, gratificações e benefícios apesar de serem considerados importantes, não são as principais fontes motivadoras do desempenho dos colaboradores, sobressaem-se também os incentivos psicológicos e sociais.

Entretanto, os Incentivos Psicológicos e Sociais explicam a percepção dos colaboradores das instituições financeiras públicas, mas com uma ênfase menor. 0 componente determinado como Cargos e Salários, detém uma variância muito próxima, apesar que no meio privado ser o último componente para explicar a percepção. Em âmbito público, a responsabilidade e desafios, é um componente observado e relevante para a variação total. Por meio dessa comparação, ficou evidente as diferenças e semelhanças da percepção dos colaboradores das instituições financeiras sobre a remuneração estratégica. Em ambas instituições, o componente mais relacionado a remuneração direta não foi o que mais evidencia a percepção dos colaboradores. Assim, a importância os demais tipos de remuneração se concretiza devido à percepção sobre 0 a práticas da remuneração estratégica adotada pelas instituições financeiras.

Além disso, os resultados também confirmam a importância dos benefícios e oportunidades propostas pelas instituições financeiras na busca de motivar os colaboradores, ideia prestigiada por Gheno e Berlitz (2011). Contudo, a prática de remuneração estratégica, mesmo que em parte, já são adotadas nessas instituições, podem servir como norte para empresas dos demais setores com o mesmo respaldo estratégico. Devido à remuneração dos colaboradores estar sofrendo alterações com o tempo (Marquart et al., 2012), um dos meios para alinhar os interesses individuais com o desempenho organizacional é a remuneração estratégica.

Embora haja diversos fatores a serem considerados quando se trata de remuneração e motivação, um sistema remuneratório elaborado de forma consistente com a realidade dos colaboradores, bem como os interesses das instituições em conjunto, pode promover a retenção e atrair colaboradores mais qualificados, 
motivados e cada vez mais produtivos. Diante disso, os gestores das organizações têm o papel de proporcionar incentivos que despertem nos colaboradores a motivação para a realização e o melhor desempenho de suas atividades, introduzindo oportunidades aos colaboradores para que estes realizem o esforço intencional, visando os resultados individuais e organizacionais.

Como limitação do estudo tem-se a restrição da percepção dos profissionais preponderantemente da área financeira e localizados na cidade de Cascavel Pr. 0 estudo mostra que há um campo a ser explorado, assim sugere-se para pesquisas posteriores, que seja desenvolvida junto aos profissionais que ocupem cargos estratégicos nas diversas organizações, uma vez que estes podem estar diretamente relacionados com os objetivos e participam da elaboração das metas e dos tipos de remuneração estratégica.

\section{REFERÊNCIAS}

Aguiar, A. B. et al. (2012). Associação entre sistema de incentivos gerenciais e práticas de contabilidade gerencial. Revista de Administração de Empresas, 52(1), pp. 40.

Aktar, S., Sachu, M. K., \& Ali, M. E. (2012). The impact of rewards on employee performance in commercial banks of Bangladesh: an empirical study. IOSR Journal of Business and Management, 6(2), 9-15.

Albergaria, A. R. (2010). Remuneração variável no setor público: estudo sobre a percepção dos servidores da secretaria de Estado de saúde de Minas Gerais sobre o prêmio por produtividade e suas relações com o desempenho funcional e adaptação social. Dissertação (Dissertação em Administração) - Centro de PósGraduação e Pesquisas da Faculdade de Ciências Econômicas, Universidade Federal de Minas Gerais, Belo Horizonte.

Anthony, R. N., \& Govindarajan, V. (2012). Sistemas de controle gerencial (12a ed.). Porto Alegre: Editora AMGH.

Appelbaum, S. H., \& Kamal, R. (2000). An analysis of the utilization and effectiveness of non-financial incentives in small business. Journal of Management Development, 19(9), 733-763.

Babbie, E. (1999). Métodos de pesquisas de survey. Belo Horizonte: UFMG.

Bebchuk, L., \& Grinstein, Y. (2005). Firm expansion and CEO pay (No. w11886). Cambridge, MA: National Bureau of Economic Research.

Beuren, I. M., Kaveski, I. D. S., \& Rigo, V. P. (2014). Associação das medidas de desempenho para pagamento de bônus aos executivos com dependência de capital humano. Revista Contemporânea de Contabilidade, 11(22).

Beuren, I. M., Silva, M. Z., \& Mazzioni, S. (2014). Remuneração dos executivos versus desempenho das empresas. Revista de Administração FACES Journal, 13(2).

Brandão, C. J., Rosa, L., \& J unior, S. (2012). Remuneração estratégica como forma de responsabilidade social interna-um estudo de caso em um comércio de telecomunicações em Tangará da Serra-MT. Revista UNEMAT de Contabilidade, 1(1).

Cardozo, R. M., Nascimento, C., \& Gasparetto, V. (2011). Evidenciação da remuneração estratégica em empresas do setor elétrico de 2003 a 2007. Revista Brasileira de Estratégia, 4(3), pp. 275-285.

Chiang, F. F., \& Birtch, T. A. (2012). The performance implications of financial and non-financial rewards: An Asian Nordic comparison. Journal of Management Studies, 49(3), 538-570.

Erbasi, A., \& Arat, T. (2012). The effect of financial and non-financial incentives on job satisfaction: An examination of food chain premises in Turkey. International Business Research, 5(10), 136.

Fávero, L. P., Belfiore, P., Silva, F. L., \& Chan, B. L. (2009). Análise de dados: modelagem multivariada para tomada de decisões. Porto Alegre: Pratice hall.

Fisher, B. F. (2010). Desafio da implementação de um plano de remuneração variável (PRV) na percepção de lideranças: o caso de uma empresa no segmento de comercialização de commodities. Dissertação (Dissertação em Administração) - Centro de Pós-Graduação em Administração da Universidade do Vale do Rio dos Sinos, Porto Alegre.

Fong, E. A., Misangyi, V. F., \& Tosi, H. L. (2010). The effect of CEO pay deviations on CEO withdrawal, firm size, and firm profits. Strategic Management Journal, 31(6), 629-651.

Gheno, R., \& Berlitz, J. (2011). Remuneração estratégica e pacote de benefícios: um estudo de caso aplicado ao nível operacional de uma multinacional. Revista de Administração da UFSM, 4(2), pp. 268-287.

Gomes Machado, D., \& Beuren, I. M. (2015). Política de remuneração de executivos: um estudo em empresas industriais brasileiras, estadunidenses e inglesas. Gestão \& Regionalidade, 31(92). 
Hair J r., J. F., Babin, B., Money, A. H., \& Samouel, P. (2005). Fundamentos de métodos de pesquisa em administração. Porto Alegre: Ed. Bookman.

Hair J r, J. F., Black, W. C., Babin, B. J., Anderson, R. E., \& Tatham, R. L. (2010). SEM: An introduction. Multivariate data analysis: A global perspective, 629-686.

Herzberg, F., Mausnes, B., Peterson, R. O., \& Capwell, D. F. (1957). Job attitudes; review of research and opinion. England: Psychological Service of Pittsburgh J ob attitudes.

Krauter, E. (2009). Contribuições do sistema de remuneração dos executivos para o desempenho financeiro: um estudo com empresas industriais brasileiras. Tese (Doutorado em Administração) - Universidade de São Paulo, São Paulo, SP, Brasil.

Krauter, E. (2013). Remuneração de executivos e desempenho financeiro: um estudo com empresas brasileiras. Revista de Educação e Pesquisa em Contabilidade (REPeC), 7(3).

Marquart, A., Lunkes, R. J., \& da Rosa, F. S. (2012). Um estudo sobre práticas de remuneração estratégica nas maiores empresas de Santa Catarina. Gestão e sociedade, 6(13), pp. 04-25.

Maslow, A. H. (1970). Motivation and personality (3th ed.). New York: Longman.

Merchant, K. A., Van der Stede, W. A., \& Zheng, L. (2003). Disciplinary constraints on the advancement of knowledge: the case of organizational incentive systems. Accounting, Organizations and Society, 28(2), 251-286.

Moers, F. (2006) Performance Measure Properties and Delegation. The Accounting Review: July 2006, 81(4), 897-924.

Murphy, K. J. (1985). Corporate performance and managerial remuneration: An empirical analysis. Journal of accounting and economics, 7(1-3), 11-42.

Nascimento, C., Franco, L. M. G., \& Cherobim, A. P. M. S. (2012). Associação entre remuneração variável e indicadores financeiros: evidências do setor elétrico. Revista Universo Contábil, 8(1), pp. 22-36.

Nichele, J., Stefano, S. R., \& Raifur, L. (2015). Análise da remuneração estratégica para atrair e reter colaboradores: a visão dos pós-graduandos. Revista de Carreiras e Pessoas (ReCaPe), 5(2).

Oyadomari, J. C. T., Cesar, A. M. R. V. C., Souza, E. F., \& Oliveira, M. A. (2010). Influências da remuneração de executivos na congruência de metas. Revista Contemporânea de Contabilidade, 6(12), pp. 53-74.

Rayton, B. A. (2003). Firm performance and compensation structure: performance elasticities of average employee compensation. Journal of Corporate Finance, 9(3), 333-352.

Reis Neto, M. T. (2004). A remuneração variável na percepção dos empregados e suas consequências na motivação e no desempenho. Tese (Doutorado em Administração) - Centro de Pós-Graduação e Pesquisas da Faculdade de Ciências Econômicas, Universidade Federal de Minas Gerais, Belo Horizonte.

Richardson, R. J., et al. (1999). Pesquisa social: métodos e técnicas (3a ed.). São Paulo: Editora Atlas.

Robbins, S. P., Judge, A. T., \& Sobral, F. (2011). Comportamento organizacional (14end ed.). São Paulo: Cengage.

Sharma, S. (1996). Applied Multivariate Techniques (1th ed.). New York: Wiley.

Vlachos, I. P. (2011). The effects of human resource practices on firm growth. Human Resource Management: Issues, Challenges and Opportunities, 108.

Vroom, V. H. (1964). Work and motivation. New York: J ohn Wiley \& Sons.

Wood Jr, T., Picarelli Filho, V. (2004). Remuneração estratégica: a nova vantagem competitiva (3a ed.). São Paulo: Editora Atlas.

Xavier, P. R., Silva, M. O., \& Nakahara, J. M. (1999). Remuneração variável: quando os resultados falam mais alto. São Paulo: Makron Books.

Watson, R. (1994). An Empirical Analysis of Financial and Non-financial Managers' Remuneration in Small and Medium-sized UK Enterprises. Accounting and Business Research, 24(94), 176-188. 